\title{
Leptoclinides (Ascidiacea, Didemnidae) from Brazil: new records and two new species
}

\author{
Livia M. OLIVEIRA ${ }^{1, *}$, João Paulo CARVALHO ${ }^{2}$ \& Rosana M. ROCHA ${ }^{3}$ \\ ${ }^{1,2,3}$ Systematics and Ecology of Marine Invertebrates Laboratory, Zoology Department, \\ Universidade Federal do Paraná, CP 19020, 81531-980 Curitiba, Brazil. \\ *Corresponding author: liviamoura87@gmail.com \\ 2Email: joaopcarvalho@ufpr.br \\ 33Email: rmrocha@ufpr.br \\ ${ }^{1}$ urn:1sid:zoobank.org:author:2058206A-50D4-4956-8888-358701793D7F \\ ${ }^{2}$ urn:1sid:zoobank.org:author:D5916EB9-A22E-4821-824C-B17B7434026D \\ ${ }^{3}$ urn:1sid:zoobank.org:author:E170DE7A-DB70-4E5B-8488-45FA680812DA
}

\begin{abstract}
Twenty-two samples of Leptoclinides Bjerkan, 1905 collected along the Brazilian coast between 1998 and 2017 were examined. Herein we describe two new species (Leptoclinides coronatus sp. nov. and Leptoclinides lotufoi sp. nov.). We also extend the distribution of L. latus F. Monniot, 1983 and report that, for the first time, L. torosus F. Monniot, 1983 was found outside its type locality.
\end{abstract}

Keywords. Biodiversity, faunal survey, taxonomy, Tunicata, West Atlantic.

Oliveira L.M., Carvalho J.P. \& Rocha R.M. 2019. Leptoclinides (Ascidiacea, Didemnidae) from Brazil: new records and two new species. European Journal of Taxonomy 572: 1-16. https://doi.org/10.5852/ejt.2019.572

\section{Introduction}

Didemnidae Giard, 1872 has nine valid genera, distributed in all the oceans and depths, of which just six have been reported in the Atlantic waters. Leptoclinides is one of the most diversified genera in this family. It was proposed by Bjerkan (1905) when he described L. faeroensis Bjerkan, 1905, which is a boreal, Atlantic Ocean species (Carlisle \& Carlisle 1954). Today, the genus is characterized by thick colonies with a wide variety of colors that can change even within the same species (Monniot 1989). Cloacal cavities are wide, with smooth or lobed common cloacal apertures (e.g., L. latus F. Monniot, 1983 and L. cavernosus Kott, 2001), or may be elevated and form a funnel or conical protuberance (e.g., L. albamaculatus Kott, 2001 and L. coelenteratus (Kott, 1962)). Typically, spicules are stellate, large (diameter $>50 \mu \mathrm{m}$ ), with conical, sometimes truncated, rays. Zooids have a tubular atrial siphon with a small opening (L. latus has an atrial languet in addition to the tube), a thorax with conspicuous muscle fibers that do not form a muscular process and a pharynx with four rows of stigmata. The testis is usually divided into several follicles, although it is undivided in the type species (L. faeroensis). The sperm duct is spiral, usually with five or fewer loose turns. Larvae, which are not gemmiparous, tend to be $>0.5 \mathrm{~mm}$ in length, and the oozooid in the larva have four rows of stigmata (Monniot et al. 1991; Kott 2001). 
The genus Leptoclinides comprises 77 valid species (Shenkar et al. 2019), of which five are known from the Atlantic Ocean (Rocha et al. 2012; Paiva et al. 2015): L. brasiliensis Michaelsen, 1923, L. crocotulus Paiva et al., 2015, L. faeroensis Bjerkan, 1905, L. latus F. Monniot, 1983 and L. torosus F. Monniot, 1983. Only two of these have been reported from coastal Brazil: L. crocotulus, currently only known from the Rocas Atoll (Paiva et al. 2015), and L. latus, described from Guadeloupe but also reported from the Arvoredo Biological Reserve in southern Brazil (Rocha et al. 2005).

Here, with this report, the distribution of two species previously known only from the western tropical Atlantic has been expanded to include Brazil. We also describe two new species. A third, previously undescribed species is presented, but we prefer not to name it due to the lack of larvae, whose diagnostics characteristics are necessary to complete the description of the species and compare it to known valid species.

\section{Material and methods}

Samples were collected from 1998 to 2017 in the states of Bahia, Espírito Santo, Rio de Janeiro, Paraná and Santa Catarina. When collected, colonies were anesthetized with menthol, and then fixed and preserved in $4 \%$ formaldehyde neutralized with sodium hydroxide. Specimens are deposited in the Zoology Department Collection at the Federal University of Paraná, Curitiba, Brazil (DZUP) and in the Prof. Edmundo E. Nonato Biological Collection of the Oceanographic Institute of the University of São Paulo (ColBio).

We identified species using the colony, zooid, larval and spicule characteristics listed in Table 1. Specimens were dissected with transverse slices ( 2 to $4 \mathrm{~mm}$ thick) of the colonies, from which we removed zooids and larvae. Following dissection, zooids and larvae were stained with Harris haematoxylin and then mounted on slides using Durcupan ${ }^{\circledR}$ resin for microscopic examination.

Spicules were separated from the tunic and examined using scanning eletronic microscopy (SEM) under a JEOL JSM-6360-LV model at the Universidade Federal do Paraná following routine procedures described in Oliveira et al. (2019).

\section{Results}

Class Ascidiacea Blainville, 1824

Order Aplousobranchia Lahille, 1886

Family Didemnidae Giard, 1872

Genus Leptoclinides Bjerkan, 1905

Leptoclinides coronatus sp. nov. urn:1sid:zoobank.org:act:0689D2DB-DD99-4CBB-82F0-C75FF8602BE4

Fig. 1

\section{Etymology}

The name of this species refers to the crown-like arrangement of the lobes on the surface of the colony around the common cloacae.

\section{Material examined}

\section{Holotype}

BRAZIL - 1 colony; Espírito Santo, Guarapari, Escalvada Island; 2041'58.77" S, 40²4'82" W; 8 m depth; 28 Mar. 2017; R.M. Rocha leg.; DZUP LEP-018, slide DZUP DID3.84. 


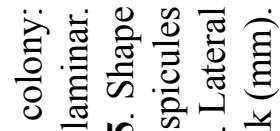
का

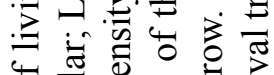

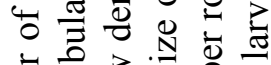
흥응

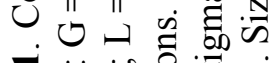

-

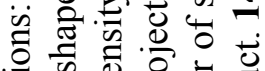
.

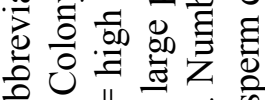
ฮे

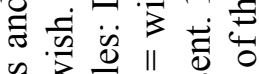

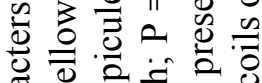

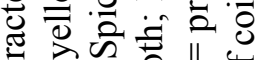

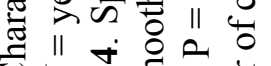
己 ڤิ) .ేี

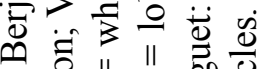
ปै 㐘 3 卷官

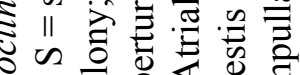
จ ป \&

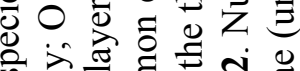

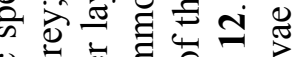
. फ़

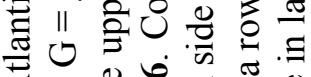

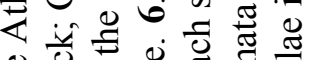
\& फे गु क्षे क्षे

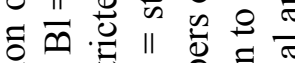
范的造. ठั

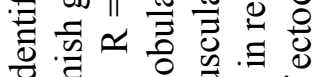
응 ‡

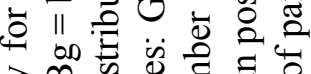
入ी:

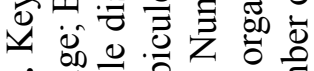
$\therefore \cdot \frac{0}{0} \frac{0}{\overline{0}} \infty \cdot \frac{0}{0}$ 을

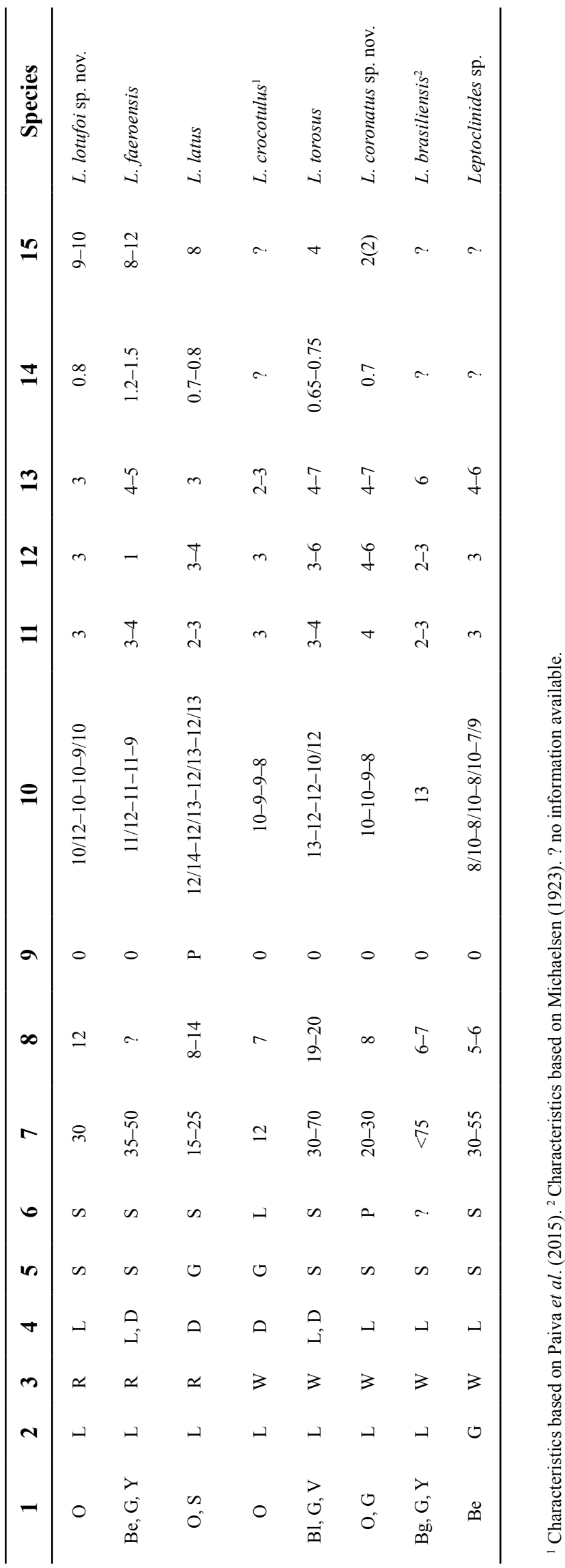


Paratypes

BRAZIL - 1 colony; Espírito Santo, Guarapari, Ilha Rasa de Terra; 2040'32" S, 40²2'1" W; $12-15$ m depth; 27 Mar. 2017; R.M. Rocha leg.; DZUP LEP-016, slide DZUP DID3.82 • 1 colony; same collecting data as for holotype; DZUP LEP-020 • 1 colony; same collecting data as for holotype but 29 Mar. 2017; DZUP LEP-019.

\section{Description}

Colonies were found exposed on granitic substrate between 8 and $15 \mathrm{~m}$. They have an orange and white marbled appearance, and colony shape follows that of the substrate (Fig. 1A). Colonies can be $2-5 \mathrm{~cm}$ in diameter and 1-2 mm thick. Color in fixed specimens becomes grayish. Common cloacal apertures are wide, white with conical projections with many spicules along the margin (Fig. 1B). The tunic is cartilaginous with a smooth surface. Spicules are $20-30 \mu \mathrm{m}$ in diameter, uniformly, but not densely, distributed throughout the tunic. Spicules are star-like with 6 conical rays in cross section and, at the base, the rays are separated from one another by a matrix covered by small, rounded projections (Fig. 1C).

Zooids are about $1.6 \mathrm{~mm}$ long, with the thorax twice the length of the abdomen. The oral siphon is tubular, $0.44 \mathrm{~mm}$ long, with six short and rounded lobes, sometimes not easily visible. On each side of the thorax there are eight muscular fibers that extend from the oral siphon to just anterior to the rectal esophageal peduncle. The atrial siphon is long and oriented downward (Fig. 1D). Occasionally the atrial opening appears short, probably due to the position of the zooid within the colony. Both siphons have conspicuous circular musculature.

The pharynx has 10 stigmata per row on each side, except the last row, which has fewer stigmata (about $8-9)$. Stigmata are narrowly fusiform and slightly wider at the center. The thoracic organ is round, not raised, normally smaller than the size of the fold and located at the level of the fourth row of stigmata, almost in the middle of the thorax. The thoracic organ is often full of spicules.

The abdomen is vertical, with a short and narrow esophagus. The stomach is large, elongate, and it is not overlapped by the intestinal loop (Fig. 1E). The testis has six rounded follicles. The sperm duct is spiral, with 4-6 counter-clockwise turns.

The larval trunk is ovoid and $\sim 0.7 \mathrm{~mm}$ in length. The tail curves $3 / 4$ of the way around the trunk. Three adhesive papillae are equally spaced with short, wide peduncles. Two pairs of large ectodermal ampullae are centrally located, and there is also one single dorsal and ventral ampullae, both smaller, for a total of six ampullae. The sensorial vesicle is posterior and the statocyte either anterior or ventral to the ocellus. Mature larvae have four rows of stigmata in the pharynx, with 10 stigmata in the first three rows and nine stigmata in the last. No pigment or ectodermal vesicles are present.

\section{Remarks}

Leptoclinides coronatus sp. nov. is very distinctive in comparison with the other congeners found in coastal Brazil. Leptoclinides crocotulus and L. latus are orange, but uniformly so and without swaths of white. Leptoclinides crocotulus is also different by the different shape and smaller $(12 \mu \mathrm{m})$ size of spicules, the different size and shape of the siphons, smaller lateral thoracic organ and three testicular follicles with two or three turns of the sperm duct (Paiva et al. 2015). It is also different from L. latus, which has a globular-type spicule, an atrial languet and fewer turns of the sperm duct.

The Australian L. imperfectus (Kott, 1962) is marbled with orange and gray on a white background, but differs more clearly from $L$. coronatus sp. nov. in having papillae on the surface of the colony, a very long esophago-rectal peduncle, 6-8 testicular follicles and seven turns of the sperm duct and slightly 

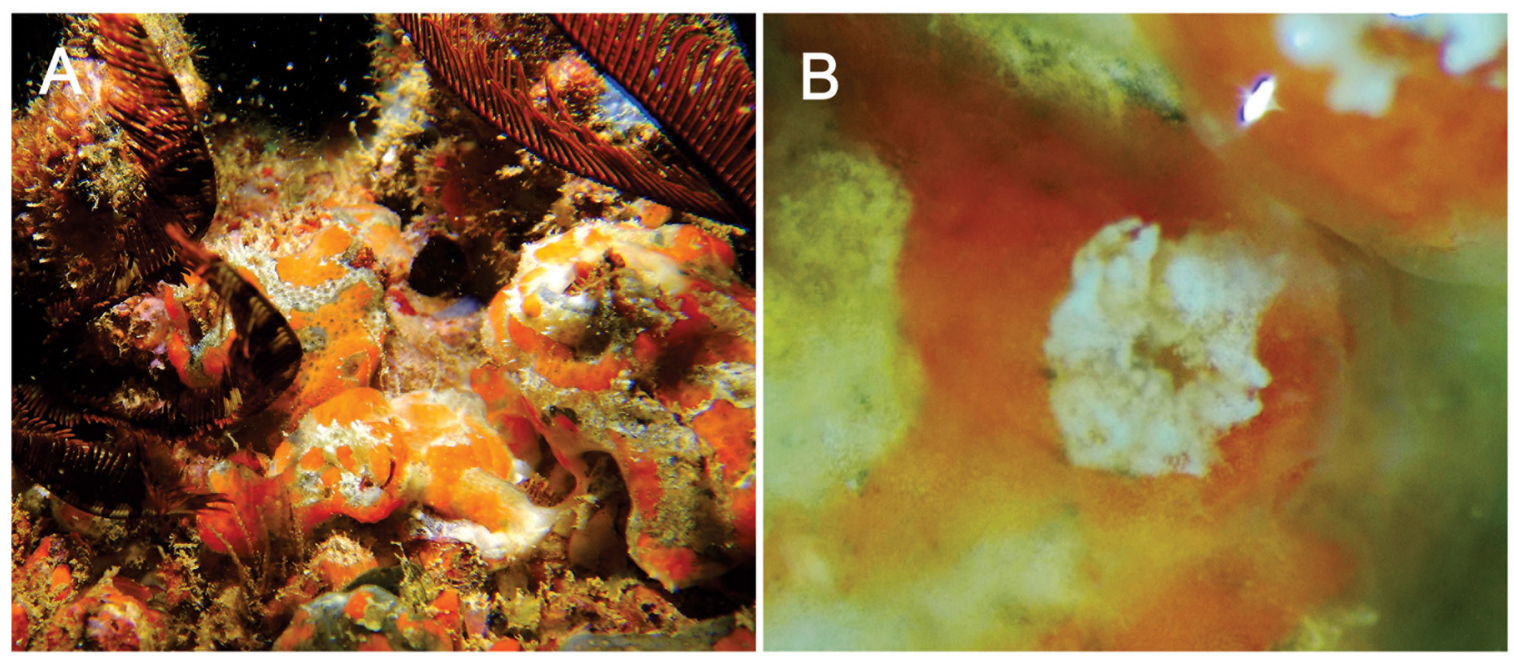
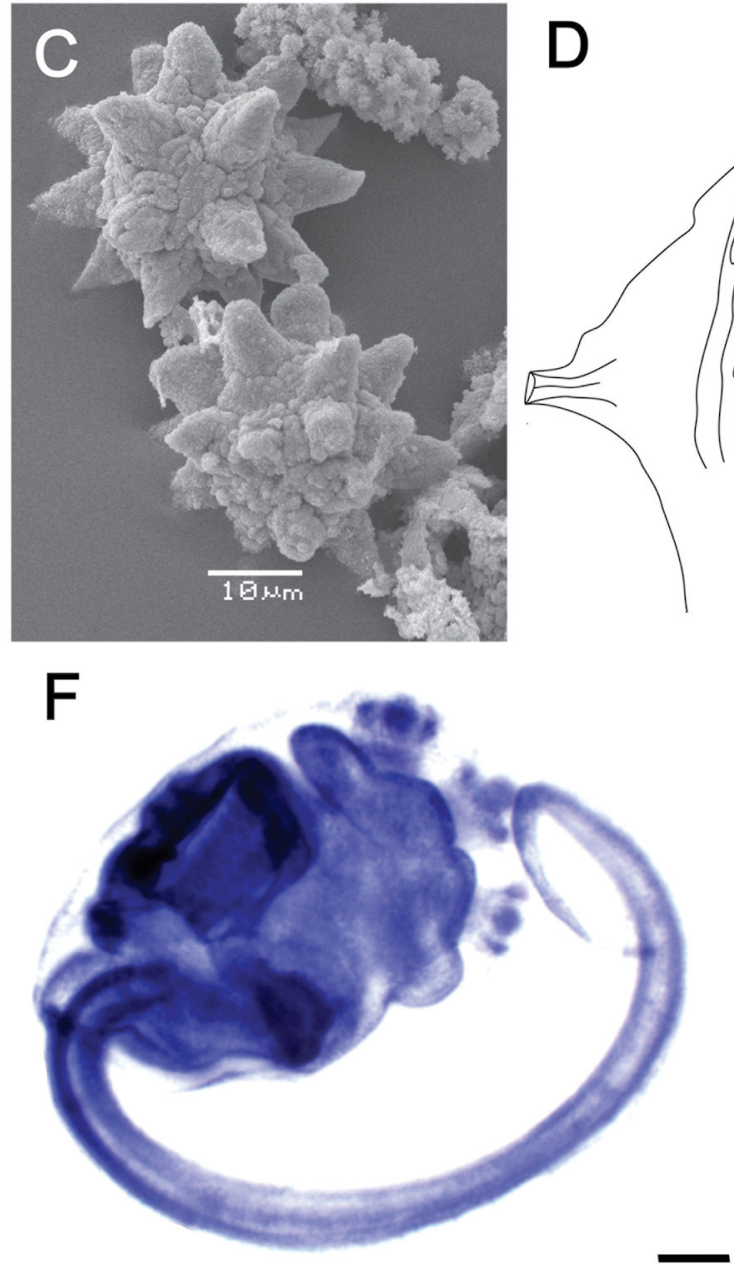

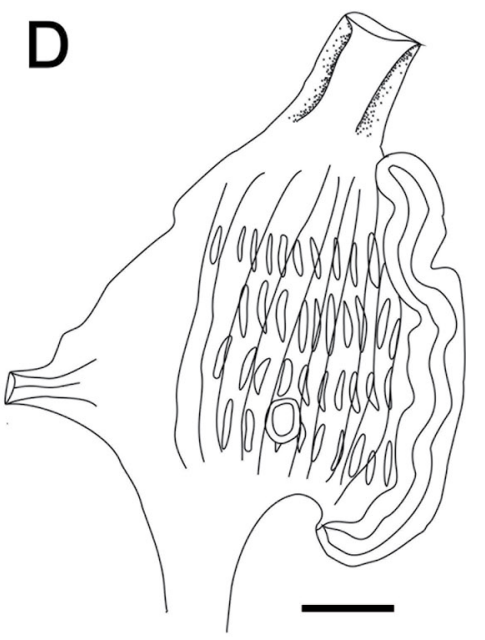

$E$

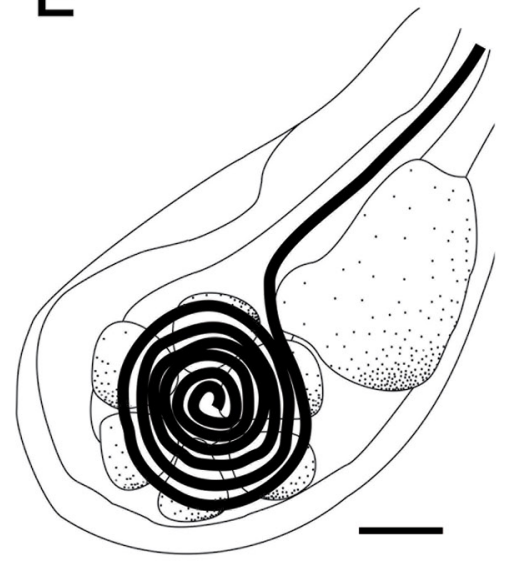

G

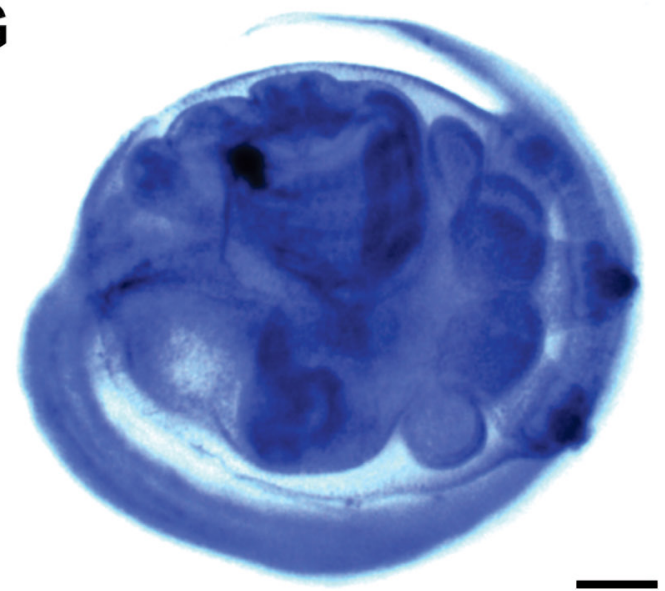

Fig. 1. Leptoclinides coronatus sp. nov., holotype (DZUP LEP-018). A. Colony in situ. B. Detail of the cloaca with lobes. C. Spicules. D. Thorax. E. Abdomen. F-G. Larvae in different stages in the same colony. Scale bars: $\mathrm{D}-\mathrm{G}=0.1 \mathrm{~mm}$. 
smaller larvae (trunk $\sim 0.6 \mathrm{~mm}$ long) with four pairs of ectodermal ampullae (Kott 2001). Also marbled, L. marmoreus Brewin, 1956 differs in having a smooth-margin cloaca and nine turns of the sperm duct (Brewin 1956), while L. marmoratum (Sluiter, 1909) is not orange, but rather gray or dark blue, has longer $(3 \mathrm{~mm})$ zooids and spicules in a narrow layer under the bladder cells, in addition to small groups of spicules scattered around the tunic (Sluiter 1909; Millar 1975).

\section{Distribution}

Type locality: Brazil: Espírito Santo.

Leptoclinides latus F. Monniot, 1983

Fig. 2

Leptoclinides latus F. Monniot, 1983: 15, fig. 4, pl. 1B.

Leptoclinides latus - Rocha et al. 2005: 468, figs 6-8.

\section{Material examined}

BRAZIL • 1 colony; Bahia, Salvador, São Marcelo Fort; 1258'6" S, 38³1'5" W; 1 Aug. 1999; R.M. Rocha leg.; DZUP DID-185, slides DZUP DID3.32, DZUP DID3.33 • 1 colony; Espírito Santo, Guarapari, Escalvada Island; 20 41'59" S, 40²4'82" W; 13 m depth; 12 Feb. 2011; R.M. Rocha leg.; under rocks; DZUP LEP-008, slide DZUP DID3.79 - 2 colonies; same locality as preceding but $20^{\circ} 42^{\prime} 00^{\prime \prime} \mathrm{S}$, 40²4'30" W; 10 m depth; 26 Jan. 2012; G.A. Gamba leg.; DZUP LEP-010, DZUP LEP-021, slide DZUP DID3.80 - 2 colonies; same locality as preceding but $20^{\circ} 41^{\prime} 58.77^{\prime \prime} \mathrm{S}, 40^{\circ} 24^{\prime} 27.82^{\prime \prime} \mathrm{W} ; 27$ Jan. 2012; 11 m depth; G.A. Gamba leg.; DZUP LEP-013, DZUP LEP-015 • 1 colony; Guarapari, Beluccia shipwreck; 2040'41" S, 40²1'41" W; 20 m depth; 28 Mar. 2017; R.M. Rocha leg.; DZUP LEP-014 • 1 colony; Rio de Janeiro, Arraial do Cabo, Saco do Cordeiro; 22 $57^{\prime} 54^{\prime \prime}$ S, 41 ${ }^{\circ} 59^{\prime} 57^{\prime \prime}$ W; 7-9 m depth; 10 Apr. 2001; R.M. Rocha leg.; under rock; DZUP DID-145 • 1 colony; Cabo Frio, Comprida Island;

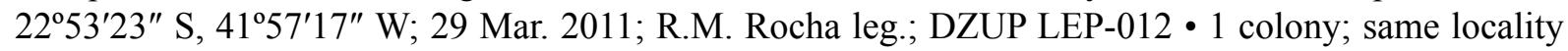

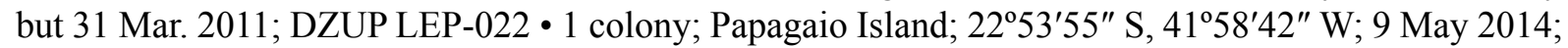
L.F. Skinner leg.; DZUP LEP-011 • 1 colony; São Paulo, São Sebastião, Alcatrazes Island; 2406'33" S, 4212'28" W; 8 m depth; 29 Jun. 2012; G.A. Gamba leg.; DZUP LEP-023 • 1 colony; Paraná, Pontal do

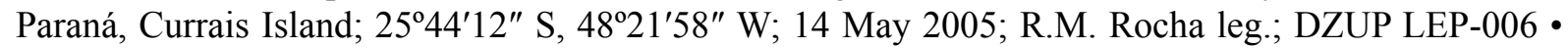
1 colony; Santa Catarina, São Francisco Sul, Graças Archipelago; 26 $6^{\circ} 10^{\prime} 51^{\prime \prime}$ S, 48 $28^{\prime} 55^{\prime \prime}$ W; 2 Apr. 2008; R.M. Rocha leg.; DZUP LEP-004 • 1 colony; Tamboretes Archipelago; 26 $23^{\prime} 03^{\prime \prime}$ S, 48 $33^{\circ} 1^{\prime 2} 5^{\prime \prime}$ W;

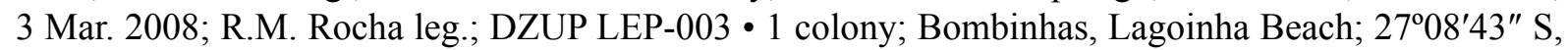
4828'50" W; 14 Feb 1996; R.M. Rocha leg.; intertidal zone; DZUP LEP-007.

\section{Description}

Colonies in situ are orangish or salmon in color, with a variation of darker or lighter forms (Fig. 2A-B), becoming white after fixation. Colonies are encrusting, with an irregular or somewhat oval outline, 3-5 $\mathrm{cm}$ wide and 2-4 mm thick and are more often found on the underside of rocks. Common cloacal apertures are large and abundant, round with a smooth border that when not well relaxed is somewhat wavy. The tunic is firm and easily broken due to abundant spicules that tend to be absent in the middle and base of the colony. In fixed colonies, the surface appears wrinkled and the oral siphons tend to become more salient. Spicules are globular, $15-30 \mu \mathrm{m}$ in diameter, with cylindrical, relatively short, blunt, irregularly pointed rays (numbering about 14 in cross section, Fig. 2C).

Zooids, about $0.8-1.2 \mathrm{~mm}$ in length, have equally long thorax and abdomen. The oral siphon is short, tubular, with six rounded lobes around the margin. The atrial siphon is small, circular and smooth, in the 
OLIVEIRA L.M. et al., Leptoclinides from Brazil
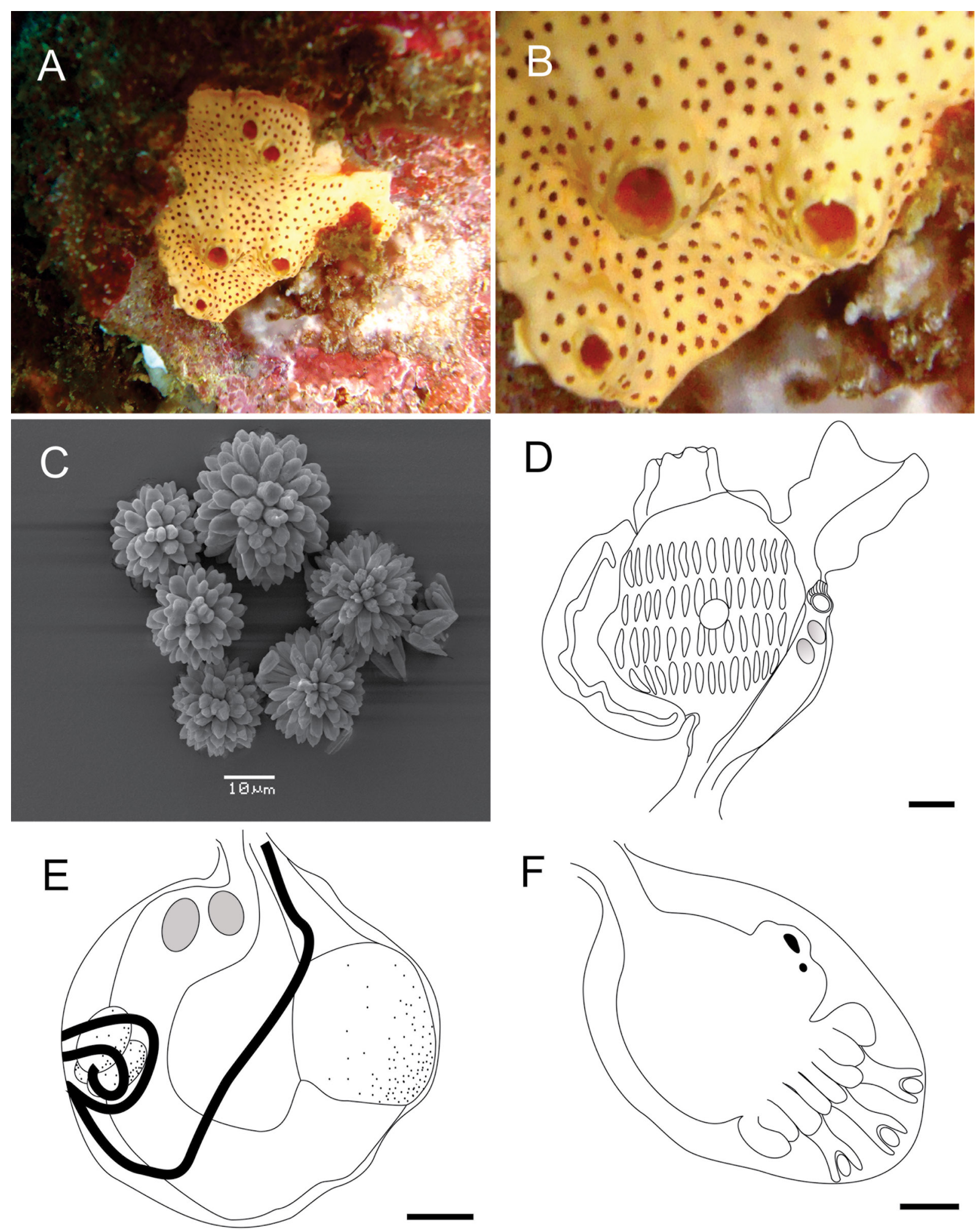

$\mathrm{F}$

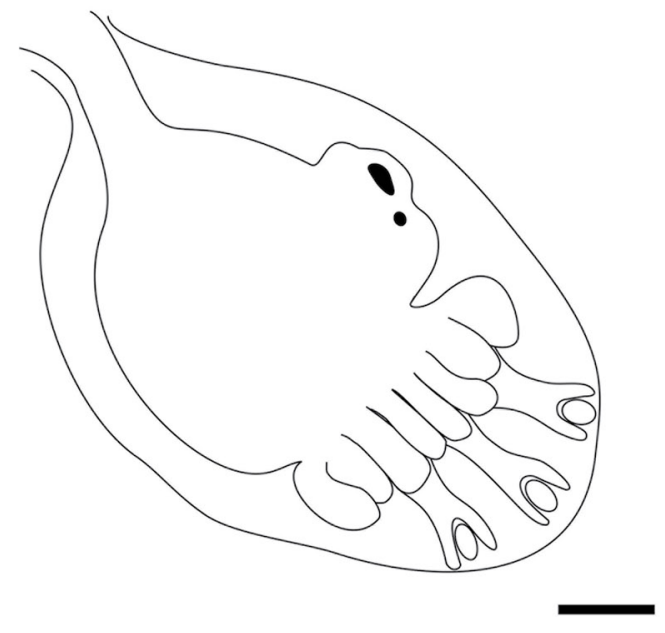

Fig. 2. Leptoclinides latus F. Monniot, 1983 (DZUP LEP-008). A. Colony in situ. B. Surface detail indicating lobed oral siphons and smooth cloacae. C. Spicules. D. Thorax. E. Abdomen. F. Larva. Scale bars: $\mathrm{D}-\mathrm{F}=0.1 \mathrm{~mm}$. 
middle of the thorax, between the second and third rows of stigmata. Some zooids have a bifurcate, wide, muscular, dorsal languet. The pharynx has 14 stigmata on each side of the first row and 13 stigmata in the remaining rows. There are six to eight muscle fibers in each side of the thorax. The thoracic organ is small, circular and between the second and third rows of the stigmata (Fig. 2D). The abdomen is vertical. The esophagus is short and narrow. The stomach is globular and is not overlapped by the intestinal loop. The testis has 3-4 small, oval follicles surrounded by two and a half or three, widely separated, turns of the sperm duct (Fig. 2E). Oocytes, present in the zooids of specimens DZUP DID-185 (Bahia) and DZUP LEP-014 (Espírito Santo), are 0.20-0.33 mm in diameter.

Larvae are oval-shaped, with a trunk $0.70-0.85 \mathrm{~mm}$ in length. Larvae have three adhesive papillae in a row, with long, slender, equally spaced peduncles, and eight pairs of elongated, ectodermal ampullae (Fig. 2F). The tail curves around $3 / 4$ of the trunk. Larvae were found in specimens collected in November in Santa Catarina and in January to March (in immature state) in Espírito Santo.

\section{Remarks}

Leptoclinides latus was first reported in the Caribbean in Guadalupe (Monniot 1983). In Brazil, it was first found at the island Arvoredo, in the state of Santa Catarina (Rocha et al. 2005). Today, the species is known to have a much wider distribution in Brazil, from Bahia to Santa Catarina, and is the most common Brazilian species in the genus Leptoclinides.

A few specimens had singular variations in characters when compared to most others. For example, the specimen from Bahia (DZUP DID-185) had a more open aperture and a longer rather than globular stomach, than is usually seen in most zooids. The colony collected in Cabo Frio (DZUP LEP-011) had five testicular follicles and the sperm duct with two turns only. Despite the variability described above, the remaining characters, including colony color, spicule size and shape, bifurcated atrial languet (where observed), and testis and larval shape and size, together clearly identify this species.

\section{Distribution}

Type locality: Guadeloupe (Monniot 1983). Other localities: Brazil: Bahia, Espírito Santo, Rio de Janeiro, São Paulo and Paraná (this study), Santa Catarina (Rocha et al. 2005).

Leptoclinides lotufoi $\mathrm{sp}$. nov. urn:1sid:zoobank.org:act:31D0C00F-2263-4826-8CEC-9782A1704D49

Fig. 3

\section{Etymology}

The name of this species is in homage to Dr Tito Lotufo for his studies in ascidian diversity in northeastern Brazil. He collected this material and lent it to us for this study.

\section{Material examined}

\section{Holotype}

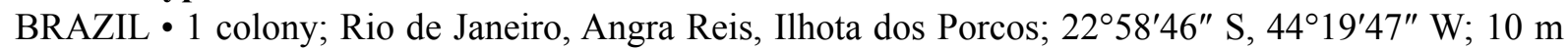
depth; 10 Oct. 1998; T.M.C. Lotufo leg.; ColBio Tun 1245.

\section{Description}

The only colony found was attached to a exposed granitic substrate around $10 \mathrm{~m}$ deep. This colony was encrusting and small ( $2 \mathrm{~cm}$ wide, $1 \mathrm{~mm}$ thick), orange, but lost most of its color when fixed in formalin (Fig. 3A). The tunic is malleable and delicate, with a wide cloacal cavity that extends from the thorax to the region of the esophago-rectal peduncle. Only one common cloacal aperture was seen in this 

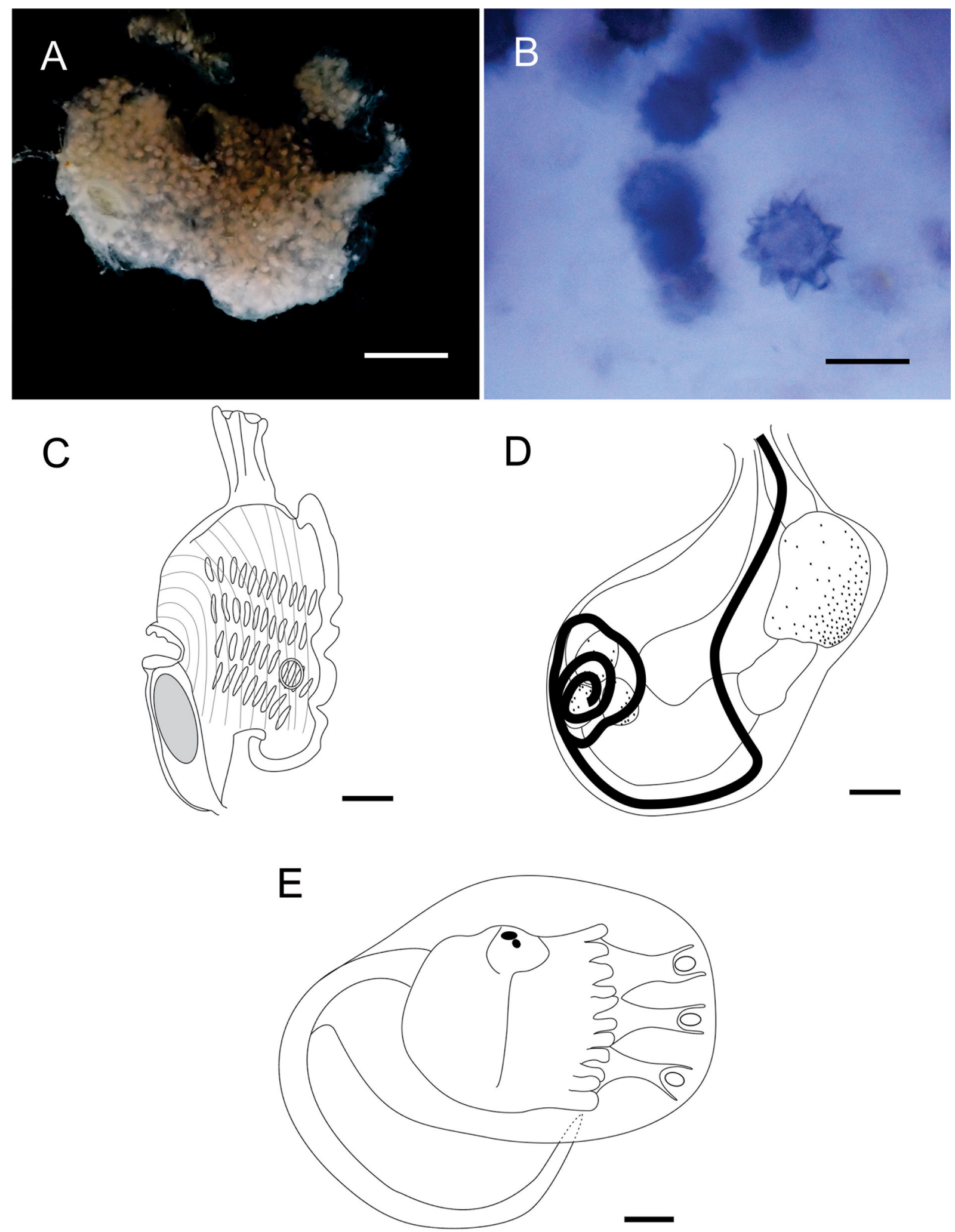

Fig. 3. Leptoclinides lotufoi sp. nov., holotype (ColBio Tun 1245). A. Preserved colony. B. Spicules under light microscope. C. Thorax. D. Abdomen. E. Larva. Scale bars: A $=0.5 \mathrm{~cm} ; \mathrm{B}=30 \mu \mathrm{m} ; \mathrm{C}-\mathrm{E}=$ $0.1 \mathrm{~mm}$. 
specimen; it is broad with a smooth margin. Spicules, in low density, almost unnoticeable, are mainly restricted to the surface layer of the tunic. Spicules are 20 to $30 \mu \mathrm{m}$ in diameter, with 10-12 (in cross section) conical, pointed rays (Fig. 3B). SEM images of the spicules could not be made because of their scarcity and the small size of the colony.

Zooids are orangish, about $1.5 \mathrm{~mm}$ long. Twelve muscle fibers run longitudinally along each side of the thorax. The oral siphon is $0.15-0.33 \mathrm{~mm}$ long with six rounded lobes. The atrial aperture is very short and opens between the third and fourth rows of the pharyngeal stigmata. The pharyngeal stigmata formula is $10-12,10,10,9-10$ per half row. The lateral thoracic organ is round, not salient, usually at about the third row of stigmata, occasionally at the second row, close to the endostyle (Fig. 3C). The stomach is slightly elongated and is not overlapped by the intestinal loop. The testis has three oval follicles, overlain by three open turns of the sperm duct (Fig. 3D).

Most of the larvae we found were immature. Larvae are oval, yellowish, with about $0.8 \mathrm{~mm}$ in trunk length, without vesicles. The tail curves about halfway around the trunk. There are three anterior adhesive papillae with long peduncles. Nine to eleven short, digitiform ampullae are on each side of the larva. The sensorial vesicle is mid-dorsal, with the statocyte somewhat anterior and ventral to the ocellus (Fig. 3E).

\section{Remarks}

Although this species is being described from one single colony, its characters were different enough from those of other known species. Leptoclinides lotufoi sp. nov. is different from the other Atlantic congeners by having the following characteristics: few spicules restricted to the surface of the colony, few testicular follicles and turns of the sperm duct, and many ectodermal ampullae in the larvae. A few other species of Leptoclinides can have many ectodermal ampullae. The Australian L. brandi Kott, 2001 has a granular colony surface with a high density of spicules and smaller larvae with eight pairs of ampullae. Leptoclinides durus Kott, 2001 has many spicules and larger larvae with eight pairs of ampullae. Leptoclinides echinus Kott, 2001 has more testicular follicles (about 15) and larger larvae with eight pairs of ampullae. From New Caledonia, L. multipapillatus Monniot, 1989 has more testicular follicles, more turns of the sperm duct and more than 20 ectodermal ampullae (Monniot 1989; Kott 2001).

\section{Distribution}

Type locality: Brazil: Rio de Janeiro.

Leptoclinides torosus F. Monniot, 1983

Fig. 4

Leptoclinides torosus F. Monniot, 1983: 17, fig. 5; pl. 1D.

\section{Material examined}

BRAZIL • 2 colonies; Bahia, Boa Viagem shipwreck; 12 $55^{\prime} 56^{\prime \prime}$ S, 38 3830'50" W; 7-8 m depth; 3 Aug. 1999; R.M. Rocha leg.; DZUP LEP-001, slides DZUP DID3.29 to DZUP DID3.31, DZUP DID-171 • 1 colony; Espírito Santo, Escalvada Island; $20^{\circ} 41^{\prime} 59^{\prime \prime}$ S, 40²4'82" W; 8 m depth; 28 Mar. 2017; R.M. Rocha leg.; DZUP LEP-017, slide DZUP DID3.83.

\section{Description}

Colonies were found on exposed granitic substrate around $8 \mathrm{~m}$ deep. Brazilian specimens form black colonies in situ (Fig. 4A-B) that when fixed turn whitish brown. Colonies are 2.5-6.0 cm wide and 2-4 mm thick. The tunic is firm, smooth and has no encrustations. Spicules are star-shaped, usually 

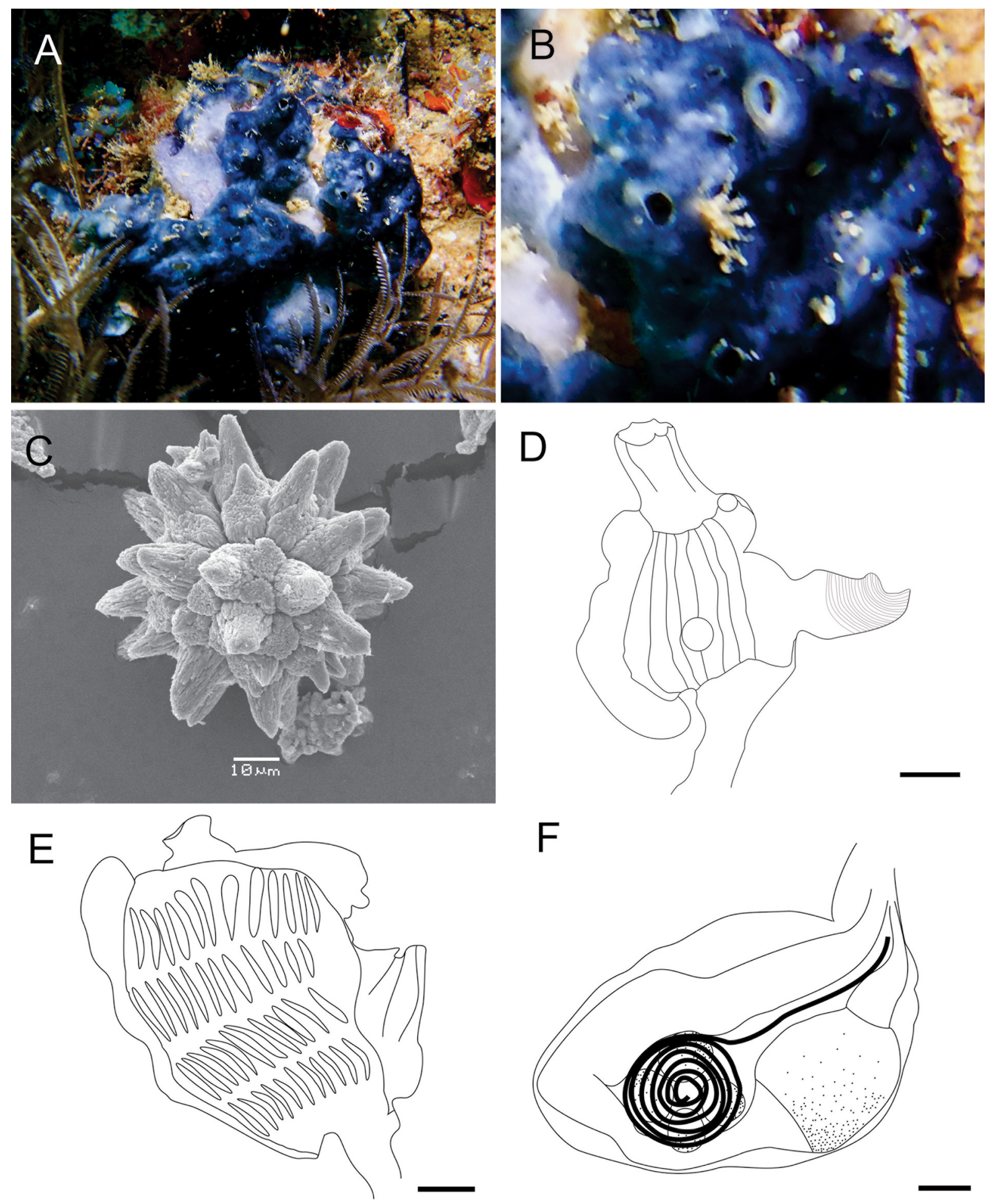

Fig. 4. Leptoclinides torosus F. Monniot, 1983. A. Colony in situ. B. Detail of the surface of the colony (DZUP LEP-017). C. Spicule. D-E. Thorax. Atrial siphon inadvertently removed during dissection in E. F. Abdomen (DZUP DID-171). Scale bars: D-F $=0.1 \mathrm{~mm}$. 
$35 \mu \mathrm{m}$ in diameter; however, the larger ones can reach $70 \mu \mathrm{m}$ in diameter. The spicules are uniformly distributed in low density in the tunic, with $8-10$, usually conical rays in cross section. Between the conical rays there are granulated areas that resemble very short truncated rays (Fig. 4C).

Zooids are $\sim 1.2 \mathrm{~mm}$ long, with a $0.5 \mathrm{~mm}$ long thorax and $0.7 \mathrm{~mm}$ long abdomen. The thorax has $7-8$ longitudinal muscle fibers on each side (Fig. 4D). The oral siphon is $0.25 \mathrm{~mm}$ long, tubular and with six short, rounded lobes along the margin. In some zooids the oral siphon is difficult to see, appearing as though it has no lobes. The atrial siphon is tubular and arises from the base of the thorax, with many circular muscle fibers (19-20) along its length. The siphon opens at the level of the fourth row of stigmata, usually downward oriented. In some zooids, the atrial and oral siphons are about the same length. The thoracic organ is circular, not salient, usually less than or the same size as the stigmata and is at the level of the third (sometimes between the third and fourth) row of stigmata. The pharynx has 12-13 stigmata on each side, in the first three rows, and 10-12 in the last row (Fig. 4E). The abdomen is horizontal, the esophagus short and narrow. The stomach is globular and is not overlapped by the intestinal loop. The testis has four, rarely five, follicles, overlain by six tightly coiled turns of the sperm duct. One specimen (DZUP DID-171, from Bahia) had a testis with four follicles and only four turns of the sperm duct.

Larvae were only found in specimens from Bahia in August. They were immature and so some structures were not visible. The larval trunk was $0.65-0.75 \mathrm{~mm}$ long and the pharynx had 9-10 stigmata per half row.

\section{Remarks}

The type location for L. torosus is Guadalupe (Monniot 1983), and here we report it for the first time in the southern Atlantic. In our samples, the colonies were thinner, and spicules were not distributed in the same way as in Guadalupe (restricted to the level of the abdomens), nor did they have papillae of spicules on the surface as in Monniot (1983). Otherwise, the color of the colony, spicule shape, number of testicular follicles, turns of the sperm duct and larval size all agree with the original description of the species.

\section{Distribution}

Type locality: Guadeloupe (Monniot 1983). Additional records: Brazil: Bahia and Espírito Santo (this study).

\section{Leptoclinides sp.}

Fig. 5

\section{Material examined}

BRAZIL • several colonies; Espírito Santo, Vila Velha, Pacotes Island; 20²1'04" S, 40¹5'12" W; $12 \mathrm{~m}$ depth; 13 Feb. 2011; R.M. Rocha leg.; DZUP LEP-009, slide DZUP DID3.81.

\section{Description}

Colonies are globular, small $(0.5-1.0 \mathrm{~cm}$ wide), beige and translucent when fixed in formalin. Many colonies were found adhering to a branching alga, attached to a horizontal surface of granitic outcrop on the bottom. Many colonies had only one common cloacal aperture, while most colonies had two (Fig. 5A-B). The tunic is smooth and soft. Spicules (30-55 $\mu \mathrm{m}$ in diameter) are low in density and uniformly distributed throughout the colony, mostly next to the surface layer. Spicules are stellate, with six to eight rays in cross-section, and rays are long and conical, with separate bases and granular patches between them (Fig. 5C). 

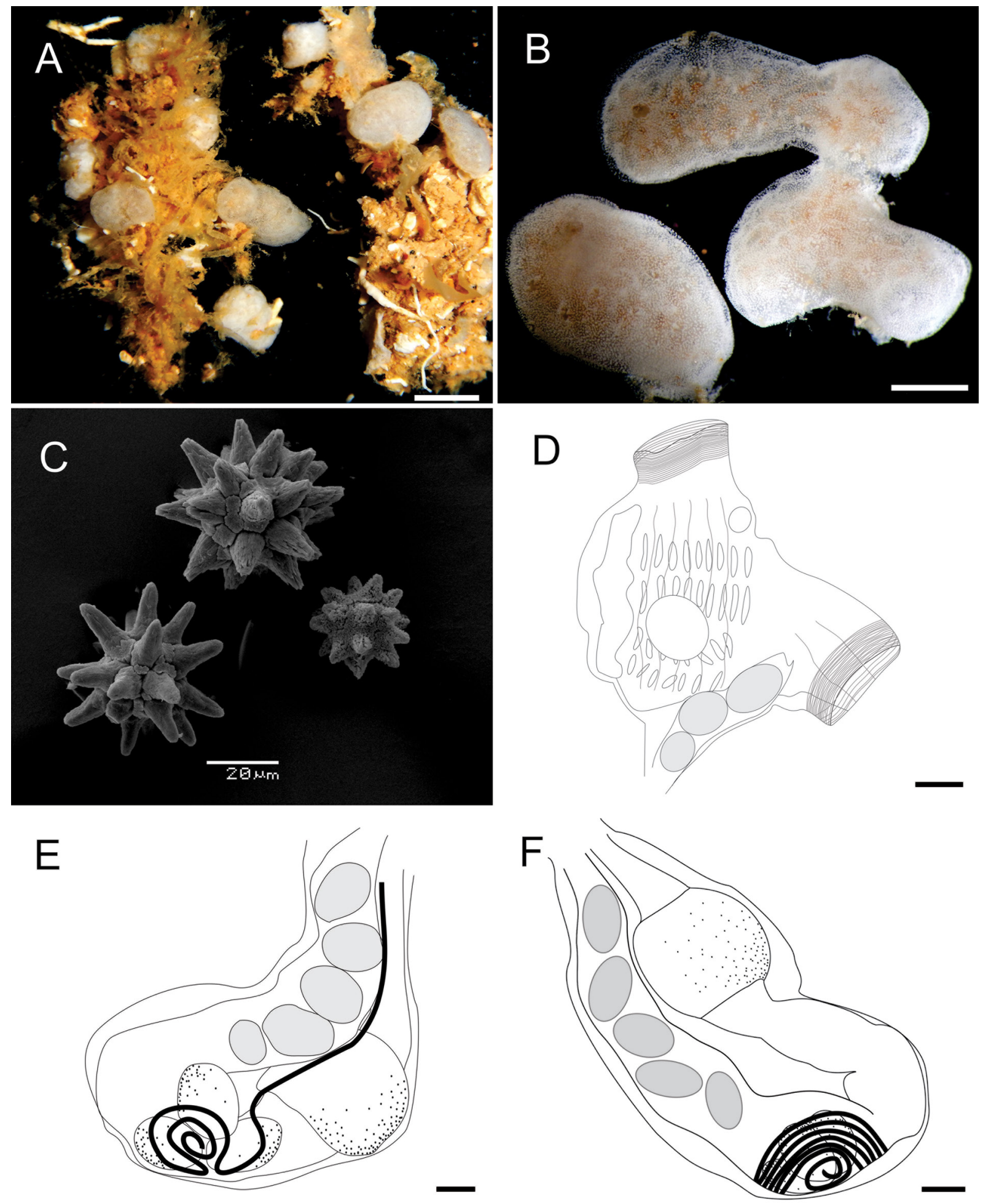

Fig. 5. Leptoclinides sp. (DZUP LEP-009). A. Preserved colony on algae. B. Detail of preserved colonies. C. Spicules. D. Thorax. E-F. Abdomen. Scale bars: A $=1 \mathrm{~cm} ; \mathrm{B}=0.5 \mathrm{~cm}$; D-F $=0.1 \mathrm{~mm}$. 
Zooids (1-2 mm long) with thorax and abdomen of about the same length. The thorax has 5-6 longitudinal muscle fibers on each side. The oral siphon is short, wide and tubular, with evident circular muscle fibers. Its margin is slightly undulate, without clear lobes. The atrial siphon is downward oriented, tubular, but with a large diameter and without lobes in the aperture. Circular muscle fibers (19-20) are conspicuous. The first three rows in the pharynx have 8-10 stigmata, while the fourth has 7-9. The thoracic organ is circular, larger than the stigmata and not salient. It is at the level of the third row of stigmata in the middle of the thorax (Fig. 5D). In some zooids the organ is full of spicules.

The esophago-rectal peduncle is usually short and narrow, but some zooids have a long esophagus. The abdomen is vertical. The globular stomach may be slightly overlapped by the intestinal loop. There are three stoloniferous vessels of different sizes, with the largest being half the length of the abdomen. The testis has three follicles, surrounded by 4-6 counter-clockwise (few zooids with clockwise direction) turns of the sperm duct (Fig. 5E-F). Larvae were absent.

\section{Remarks}

This lot was different from all others from Brazil or the Atlantic Ocean. A unique feature of this species was the globular, aggregated, small colonies. Despite their color, stellate spicule shape and male reproductive system, all of which are similar to those of L. brasiliensis, this species comprises a thin encrusting colony, with larger $(2 \times)$ spicules, and an atrial siphon with a smaller diameter. While we suspect that this may be an undescribed species, we prefer not to name it here, due to the lack of diagnostic larvae and the few colonies we examined. It is possible that all the colonies we examined are part of the same clone and arose by fission, which is suggested by its aggregation, the small colony size and the usually single common cloaca.

\section{Distribution}

Brazil (Espírito Santo).

\section{Discussion}

Leptoclinides is the third most species-rich genus in the Didemnidae (Shenkar et al. 2019), yet only five species were previously known from the Atlantic Ocean (Rocha et al. 2012). The greatest number of species are known from the Indo-Pacific region and Australia (Kott 2001, 2004). The three species found in Brazil increase by almost 50\% the species richness in the Atlantic Ocean and L. latus is the most common species of the genus in Brazil. Of the species described herein, only L. latus was found farther south than $20^{\circ} \mathrm{S}$, and the rest are restricted to tropical waters. Given that didemnids are usually neglected in general surveys because of identification difficulties, we expect to find more new species in Atlantic tropical waters with further collections and study by specialists.

\section{Acknowledgments}

We thank Linda Cole for receiving RMR at the National Museum of Natural History, Smithsonian Institution and for the logistic support as well as financial support by NSF grant DEB-1456674 to Rachel Collin: "Advancing Revisionary Taxonomy and Systematics: Integrative Research and Training in Tropical Taxonomy". We thank Tito M.C. Lotufo, who shared his material with us. CNPq (National Council for Scientific and Technological Development) provided financial support for RMR (PROTAX 440429/2015-3, 445783/2014-1, 305201/2014-0), LMO (141490/2014-4, 153253/2018-5) and JPC (117282/2018-9). FAPESP supported field work under the project Components of Biodiversity and their Metabolic Characters in Brazilian Islands - an integrated approach, coordinated by Dr Roberto G.S. Berlinck (13/50288-8). 


\section{References}

Bjerkan P. 1905. Ascidien vom norwegischen Fischereidampfer 'Michael Sars' in den Jahren 1900-1904 gesammelt. Bergens Museums Aarbog 5: 1-29. Available from https://biodiversitylibrary.org/page/41771160 [accessed 7 Oct. 2019].

Brewin B.J. 1956. Ascidians from the Chatham Islands and the Chatham Rise. Transactions of the Royal Society of New Zealand 84 (1): 121-137.

Carlisle D.B. \& Carlisle A.I. 1954. Notes on the Didemnidae (Ascidiacea): I. The presence of Didemnum (Leptoclinides) faeröense (Bjerkan) in the Plymouth area. Journal of the Marine Biological Association of the United Kingdom 33: 21-25. https://doi.org/10.1017/S002531540000343X

Kott P. 2001. The Australian Ascidiacea. Part. 4: Aplousobranchia (3), Didemnidae. Memoirs of the Queensland Museum 47(1): 1-410. Available from https:/www.biodiversitylibrary.org/page/40460926/page/3/mode/1up [accessed 6 Nov. 2018].

Kott P. 2004. New and little-known species of Didemnidae (Ascidiacea, Tunicata) from Australia (part 1). Journal of Natural History 38 (6): 731-774. https://doi.org/10.1080/0022293321000041725

Michaelsen W. 1923. Neue und altbekannte Ascidien aus dem Reichsmuseum zu Stockholm. Mitteilungen aus dem Zoologischen Staatsinstitut und Zoologischen Museum in Hamburg 40: 1-60.

Millar R.H. 1975. Ascidians from the Indo-West-Pacific region in the Zoological Museum, Copenhagen (Tunicata, Ascidiacea). Steenstrupia 3 (20): 205-336.

Monniot C., Monniot F. \& Laboute P. 1991. Coral Reef Ascidians of New Caledonia. Editions de l'ORSTOM, Faune Tropicale 30.

Monniot F. 1983. Ascidies littorales de Guadeloupe I. Didemnidae. Bulletin du Muséum national d'Histoire naturelle, 4' ème Série 5A (1): 5-49.

Monniot F. 1989. Ascidies de Nouvelle-Caledonie. 7. Les genres Atriolum et Leptoclinides dans le lagon sud. Bulletin du Muséum national d'Histoire naturelle, $4^{\text {ème }}$ série 11A (4): 673-691.

Oliveira L.M., Hoeksema B.W. \& Rocha R.M. 2019. Polysyncraton (Ascidiacea, Didemnidae): a reexamination of some specimens and description of three new species. European Journal of Taxonomy 519: 1-25. https://doi.org/10.5852/ejt.2019.519

Paiva S.V., Oliveira-Filho R.R. \& Lotufo T.M.C. 2015. Ascidians from Rocas Atoll, northeast Brasil. Frontiers in Marine Science 2: 1-20. https://doi.org/10.3389/fmars.2015.00039

Rocha R.M., Moreno T.R. \& Metri R. 2005. Ascídias (Tunicata, Ascidiacea) da Reserva Biológica Marinha do Arvoredo, Santa Catarina, Brasil. Revista Brasileira de Zoologia 22 (2): 461-476. https://doi.org/10.1590/S0101-81752005000200024

Rocha R.M., Zanata T.B. \& Moreno T.R. 2012. Keys for the identification of families and genera of Atlantic shallow water ascidians. Biota Neotropica 12: 269-303.

https://doi.org/10.1590/S1676-06032012000100022

Shenkar N., Gittenberger A., Lambert G., Rius M., Rocha R.M., Swalla B.J. \& Turon X. 2019. Ascidiacea World Database. Available from http://www.marinespecies.org/ascidiacea [accessed Jan. 2019]. https://doi.org/10.14284/353

Sluiter C.P. 1909. Die Tunicaten der Siboga Expedition. Pt II. Die merosomen Ascidien. Siboga Expeditie 56B: $1-112$. 
Manuscript received: 28 May 2019

Manuscript accepted: 22 August 2019

Published on: 29 October 2019

Topic editor: Rudy Jocqué

Desk editor: Pepe Fernández

Printed versions of all papers are also deposited in the libraries of the institutes that are members of the EJT consortium: Muséum national d'Histoire naturelle, Paris, France; Meise Botanic Garden, Belgium; Royal Museum for Central Africa, Tervuren, Belgium; Royal Belgian Institute of Natural Sciences, Brussels, Belgium; Natural History Museum of Denmark, Copenhagen, Denmark; Naturalis Biodiversity Center, Leiden, the Netherlands; Museo Nacional de Ciencias Naturales-CSIC, Madrid, Spain; Real Jardín Botánico de Madrid CSIC, Spain; Zoological Research Museum Alexander Koenig, Bonn, Germany; National Museum, Prague, Czech Republic. 